\title{
TRADITIONAL AND ALTERNATIVE THERAPY FOR MENTAL ILLNESS IN JAMAICA: PATIENTS' CONCEPTIONS AND PRACTITIONERS' ATTITUDES
}

\author{
Caryl C.A.B. James ${ }^{\mathrm{a}}$ and Karl Peltzer* ${ }^{\mathrm{b}}$
}

\author{
${ }^{a}$ Department of Sociology, Psychology and Social Work, The University of the West Indies, Mona

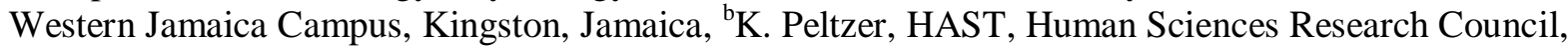 \\ Pretoria, South Africa and Department of Psychology, University of Limpopo, Turfloop, South Africa \\ *Email: $\underline{\text { KPeltzer@hsrc.ac.za }}$
}

\begin{abstract}
The aim of this study was to investigate traditional and alternative therapy for mental illness in Jamaica: patients' conceptions and practitioners' attitudes. The sample included 60 psychiatric patients selected from Ward 21 at the University of the West Indies, Kingston as well as Princess Margaret outpatient clinic, and 30 Afro-centric psychiatric nurses, psychiatrist and clinical psychologists from Kingston and St. Thomas, Jamaica. Patients were interviewed with the Short Explanatory Model Interview (SEMI) and practitioners completed a self administered questionnaire on attitudes towards traditional and alternative medicine. Results indicate that among psychiatric patients more than a third expressed the belief that the overall cause of their mental illness was as a result of supernatural factors. In general, the majority of patients felt that their perception of their problems did not concur with the western practitioner, which in turn caused distress for these patients. In case for those who also sought traditional medicine, they were more inclined to feel pleased about their interaction and the treatment they received. Results from western trained practitioners found that although they acknowledged that traditional medicine plays a major role in the treatment of mental illness among psychiatric patients the treatment was not advantageous. For the most part when all three traditional approaches were examined alternative medicine seemed more favourable than traditional healing and traditional herbal treatment. There is a need to develop models of collaboration that promote a workable relationship between the two healing systems in treating mental illness.
\end{abstract}

Key words: Psychiatric patients, psychiatric practitioners, conceptions of illness, attitude, traditional medicine, alternative medicine, Jamaica.

\section{Introduction}

Dre: The doctors say it was hallucination, but I know I wasn't hallucinating, for me that was an encounter with some supernatural stuff... to tell you the honest truth, I really don't think I have an illness, because of how the spiritual aspect of life [connect] and the physical aspect of life (pauses). I understand that because of this spiritual experience it leaves physical marks. That's where the doctors come in, they treat whatever marks, whatever scars exist ((James, 2008, p.161).

It is not unusual for a Jamaican psychiatric patient such as Dre to discount his psychiatric diagnosis and attribute his illness to supernatural causes. In fact, in Jamaica for decades there has been a controversial debate as unlike their patients, western medical practitioners, view traditional medicine as harmful and are not inclined to recommend this treatment to their patients. For these patients traditional medicine has a strong cultural tie representing a part of their African heritage and is held in high esteem (Beaubrun, 1966; Hickling, 1975; Weaver, 2003).

The patients' perception of the causes of mental disorders is relevant as it will impact on the patients' help-seeking behaviours and response to treatment. For example in Malaysia the belief that one's mental illness is caused by supernatural forces resulted in greater use of traditional healers and less compliance with the medication provided by Western biomedical sciences (Razali, Khan and Hasanah, as cited in Jorm, 2000). A similar pattern was also found in South Africa where psychiatric patients who believed that their illness was due to supernatural forces were more likely to seek spiritual and herbal healing for the treatment of their ill health (Sharif and Ogunbanjo, 2003). Patients in developing countries appear to seek traditional medicine as a part of their treatment regime not only because they believe that their illness is as a result of supernatural forces but also because they believe in the effectiveness of traditional treatments (Peltzer and Machleidt, 1992).

It has often been argued that patients also incorporate traditional medicine along with western biomedicine into their treatment. This is to gain a holistic treatment of the physical mental and spiritual. Traditional medicine is needed for the spiritual, whereas western biomedicine is needed for the physical (Rowe and Allen, 2003). The spiritual dimension forms an integral part in the individual's worldview that conditions the person's interpretation, comprehension and reaction to life experiences. This would explain why individuals will turn to their religious faith when ill (Rowe and Allen, 2003).

In some societies that have a strong African heritage, psychiatric patients simultaneously seek treatment from the traditional healers alongside western practitioners (Peltzer, 2001). Jamaicans also follow this pattern in treating their ill health (Wedenoja, 1983). In Jamaica traditional medicine is practiced in secrecy and is frowned upon by those who are unaware of the nature of its 
practice. The lack of knowledge in traditional medicine is further prevented because it is illegal to utilize traditional medicine. The practice of Obeah in Jamaica is illegal, based on the Obeah Act passed in 1898. The Obeah Act of 1898 states that anyone who uses or pretends to use supernatural powers or knowledge is liable to imprisonment with or without hard labour for a period not exceeding 12 months and in addition to or in lieu of whipping. This law extends to other individuals who are seeking help from the Obeah man/woman and individuals assisting in anyway (Ministry of Justice, Jamaica 2006). This coupled with the fact that it is seen as socially unacceptable results in the paucity of research in this area. The term "Obeah" is currently used in a loose and vague manner to include practices under the sphere of traditional health and traditional medicine (Weaver, 2003). Despite the stigma and legal repercussions attributed to using Obeah, the majority of psychiatric patients admitted to using traditional medicine in the treatment of their ill health (James, Weaver \& Morgan, 2004).

Religion is one of the key features in traditional medicine. Jamaicans are known for being extremely religious. During the era of slavery there were no Christian missionaries on the island therefore for the first 150 years a set of pan-tribal religious institutions were developed. Around the 1800 the Methodist, Baptist, and Presbyterian missionaries began to arrive which led to Afro-Protestant syncretic cults. Subsequently the American evangelical and Pentecostal sects became formidable movements (Wedenoja, 1983). The religious rituals practiced in the Pentecostal sects usually involve faith healing by group prayer and the laying of hands. Syncretic revival or pocomania cults engage in healing more specifically through a form of herbalism called balm. In 1968 Marriot did a survey and although these figures are a gross underestimation and quite dated. He indicated that at the time $32 \%$ of the patients believed in balm healing and $8 \%$ had visited a balmist.

Jamaican practitioners mainly those of the middle classes or social elite, are usually unaware of the significance of traditional beliefs and practices to their patients (Beaubrun, 1966). To further reiterate this point, Weaver (2003) stated that "young, intelligent people are drawn from the various cultures to undergo intense education and training in the Western biomedical sciences. After training, these health workers return to their respective culture to practice their skills" (Weaver, 2003, p.44).

It is unfortunate that the training for Jamaican practitioners does not take into account educating practitioners on traditional beliefs and practices as it is likely that they will encounter patients who are of strong conviction of the impact of traditional medicine. Lack of knowledge and understanding can therefore become problematic for western practitioners when faced with patients who utilize traditional methods but also speak the traditional language which includes terms such as: "eyes dark", "bad feeling", "get out of self", "act ignorant" or "take it on the brain" (Beaubrun, 1976 as cited in Wedenoja, 1983). Hickling (1975), noted this problem at an international level where foreign practitioners frequently diagnose personality disorders in patients who speak this traditional language. Examples of this were demonstrated by Wittkover (1970) and (Kiev, 1963); in that the West Indian culture is one that entails the endorsement of paranoid beliefs therefore when Jamaicans attribute their illness to sorcery. These cultural expressions are often labelled religious delusions and hallucinations in psychiatry as they resemble the symptoms that are present in schizophrenic and manic patients. When patients experience symptoms such as withdrawal and noisy, aggressive behaviours, they frequently believe that the causes are demon-possession or sorcery and usually seek treatment from the traditional healers (Beaubrun, 1976 as cited in Wedenoja, 1983).

The aim of this study was to investigate traditional and alternative therapy for mental illness in Jamaica. Research questions include: How do psychiatric patients conceptualize their own mental illnesses? What are practitioners' attitudes towards traditional and alternative medicine?

\section{Methods \\ Design}

This is a mixed method study, which incorporates both quantitative and qualitative methods of research. A sample of psychiatric patients were interviewed with an open-ended questionnaire and a sample of practitioners filled in a self-administered questionnaire. Sample and procedure: patient participants

Psychiatric patients were selected from Ward 21 at the University of the West Indies, Kingston as well as Princess Margaret outpatient clinic. These were 30 males and 30 females ranging from ages 17 to 72 with a mean age of 35 . These psychiatric patients included both inpatients and outpatients and had a diagnosis of one of the following disorders: schizophrenia, brief psychotic disorder, or affective disorders. Patients were included in the study only if indicated by the head psychiatric nurse as being psychologically oriented (that is the psychiatric illness would not affect the validity of their responses) to engage in interview. They read or had the informed consent read to them after which they signed with a witness present. Ethics approval was obtained from the University of the West Indies.

Interviewees were encouraged to talk openly about their attitudes towards and experience of current mental illness with the aim of eliciting beliefs held. Specific probes were then employed to confirm any beliefs mentioned in response to the open-ended questions and to explore areas in which comments have been volunteered. The interviews were not audio recorded as it was felt it would be culturally too sensitive and could adversely affect the study participation. Therefore interviews were noted verbatim.

Measures: patient participants

The Short Explanatory Model Interview (SEMI) (Llyod et al., 1998) was used to answer the research question of 1) "What do psychiatric patients attribute to their mental illness and what are these causes?" The SEMI is an open-ended questionnaire consisting of ten semi-structured questions. The interview is divided into five sections to cover 1) the subject's background, 2) nature of presenting problem, 3) help-seeking behaviour, 4) interaction with physician/healer and 5) beliefs related to mental 
illness. The individuals' beliefs related to the nature of the presenting problems are examined in detail and include the reason for consulting the practitioner, the name of the problem, the perceived causes, consequences and severity, and its effects on body, emotions, social network, home life and work. The SEMI also evaluates help-seeking behaviour, especially contact with alternative non-medical sources and the details of the interaction with the physician/healer in terms of expectation and satisfaction. As the name implies it is short and simple and the patient can provide short answers that are easily coded (Bhui and Bhugra, 2002). Its format also allows for qualitative and quantitative analysis. In addition, demographic and diagnostic characteristics of patients were assessed.

\section{Sample and procedure: western practitioner participants}

A survey was conducted on 30 western trained mental health practitioners employed to the University of the West Indies. The researchers opted to include equal numbers of practitioners in each group these included psychiatric nurses (10), psychiatrists (10) and clinical psychologists at the masters or doctoral level (10) which resulted in a total of 30 participants. After practitioners were located the researchers gave a description of the study to each practitioner and after written consent was obtained from the practitioner, the practitioner was included and became a part of the sample until the sample size of thirty (30) practitioner participants were accounted for. Each practitioner completed the self administered questionnaire. Ethics approval was obtained from the University of the West Indies.

\section{Measures: western practitioner participants}

The Physicians' attitudes about and practice of complementary and alternative medicine Questionnaire, containing 6 sections (Boucher and Lenz, 1998) was used. Section 1 included demographic and practice data: sex, age, number of years of medical practice, and ethnicity. Section 2 had 8 items on the perceptions about traditional medicine, 8 items on faith healing and 8 items on alternative medicine. Section 3 asked for referral information: 3 items on referrals to traditional healer, 3 items on faith healer and 3 items on alternative medicine practitioner; 6 items for each non-biomedical method for possible reasons for referral; and 8 items on discussing benefits and harmful effects for each non-biomedical method. Section 4 identified the knowledge about various non-biomedical treatment methods, etc. Finally, practitioners were required to answer open-ended questions of cases where they knew of patients who had consulted a traditional healer, faith healer or alternative medicine practitioner before consulting the bio-medical practitioner. In addition, demographic and practice characteristics of the practitioners were assessed.

\section{Data analysis}

The Statistical Package for Social Sciences (SPSS version 18.0 for Windows; SPSS Inc., Chicago, IL, USA) was used for data analyses. Descriptive statistics were used for frequency analyses from both psychiatric patients and practitioner samples. The qualitative data from the Short Explanatory Model Interview (SEMI) was coded using the coding manual (Sumathipala et al. 2008). Another clinical psychologist independently co-rated 15 randomly selected patients for reliability and comparability. The qualitative data generated from the SEMI were converted into numerical codes by the method of stepwise reduction of data to discrete categories and were entered in to a SPSS spread sheet.

\section{Results}

\section{Patient sample characteristics}

As illustrated in Table 1 a total of 60 patient participants participated in the study half of which were males. The majority were within the 17-30 age group. In addition to seeking western treatment half of the participants also used traditional medicine. There were different psychiatric diagnoses the largest group of which were paranoid schizophrenic (21/60).

\section{Practitioner sample characteristics}

As shown in Table 2, the practitioner sample consisted of more than two thirds females (22/30). The majority of which fell within the middle to later adulthood age group of 31-51 and over age group (24/30). There were equal numbers of psychiatrists (10), psychiatric nurses (10) and psychologists (10) who participated in the study. A little over two thirds revealed that they practiced their religion often-very often (18/26). Western practitioners tend to practice largely in the urban setting $(18 / 30)$. Practitioners vary in the types of treatment they provide their patients with, however the results reflect three modes of treatment that seems to be common these include: medicine and psychotherapy (11/30), psychotherapy (10/30), medical (7/30). It should be noted that one practitioner admits to also incorporating spiritual healing (1/30) in his treatment of patients. 
Table 1: Demographics and characteristics of Patient Participants $(\mathrm{N}=60)$

\begin{tabular}{|l|c|c|}
\hline Variable & $\mathrm{N}$ & \\
\hline Gender & 30 & 50 \\
Females & 30 & 50 \\
Male & & 60 \\
Age & 36 & 40 \\
$17-30$ & 24 & 35 \\
$31-51$ \& over & & 18.3 \\
Diagnosis & 21 & 23.3 \\
Paranoid Schizophrenia & 11 & 16.7 \\
Major Depression & 14 & 6.7 \\
Bipolar & 10 & 50 \\
Psychosis & 4 & 50 \\
Generalized Anxiety & & 50 \\
Treatment & 30 & \\
Western Medicine & 30 & \\
Traditional and Western Medicine & & \\
\hline
\end{tabular}

Table 2. Demographics and practice characteristics of Western practitioner participants $(\mathbf{N}=30)$

\begin{tabular}{|l|c|c|}
\hline Variable & N & \\
\hline Gender & 22 & 73.3 \\
Females & 8 & 26.7 \\
Male & & 20.0 \\
Age & 6 & 80.0 \\
$18-30$ & 24 & 33.3 \\
31- 51 \& over & & 33.3 \\
Occupation & 10 & 33.3 \\
Psychiatrist & 10 & 69.2 \\
Psychiatric Nurse & 10 & 30.8 \\
$\quad$ Psychologist & 18 & \\
Practice Religion & 8 & 60 \\
Often-Very Often & & 20 \\
Once in a While & 18 & 20 \\
\hline Area of Practice & 6 & 36.7 \\
Urban & 6 & 33.3 \\
Rural & & 23.3 \\
Both & 11 & 3.3 \\
Method of Treatment & 10 & 3.3 \\
Medical and psychotherapy & 7 & \\
Psychotherapy & 1 & \\
Medical & 1 & \\
Psychotherapy, Spiritual Healing & & \\
Psychiatry, Psychodrama & & \\
\hline
\end{tabular}

\section{Patients' conceptions of mental illness}

Analysis of the data indicated five salient reasons why participants last visited a practitioner. The strongest theme as reported by more than two thirds of the participants (42/60) was that they felt that they could not function. Other common reasons (revealed by about a third of participants) were that they visited due to psychiatric (22/60), as well as supernatural reasons (21/60). A further third expressed that they were taken by someone to the practitioner and had not necessarily come of their own free will (20/60). Only 11 out of 60 participants felt that they received treatment because of nervous breakdown. Further, five major themes emerged as it relates to the names participants gave to their experiences. This indicates that not all participants were in agreement with the psychiatric diagnosis given and as such have a different conceptualization. In fact, only 15 of the 60 
participants believed that their experiences could be classified as a psychiatric disorder. A smaller proportion of 13 out of 60 refuted their experience being called a psychiatric disorder and 8 out of 60 revealed the belief that it was "just an illness". It seems as though they could more so identify with the experience being a nervous breakdown or stress as 26 out of 60 felt that this was the case. Others were of the opinion that their experiences were as a result of demonic/supernatural attack (16/60).

The participants were aware of when their difficulties began. This yielded five common responses. For the most part, the participants felt that the experience was recent (24/60). Others felt that the problems occurred during or after high school (20/60). Ten out of sixty felt that it was during or after college, and a smaller proportion felt that they were born with it (7/60). Lastly, only 2 out of 60 could not remember.

The salient themes emerging from the data showed four core reasons why participants felt that their problems started when they did. More than a third of the participants felt that their problems began as a result of spiritual/supernatural reasons or being in a stressful environment (26/60). Only 3 out of 60 believed that it was because of a physical illness they had experienced and 2 out of 60 revealed that it was the resurfacing of a significant past event. For the participants who felt that there were things that they had done or not done to cause the problems to occur, the following themes emerged. Some felt that it was as a result of their inefficient ability to cope with stress $(8 / 60)$ or not being mentally strong enough (7/60). Others felt that it was their involvement in spiritual rituals which had made them vulnerable (6/60). Participants also reported that they felt that smoking weed $(2 / 60)$ or a family history of the sickness $(2 / 60)$ had precipitated their current condition. When participants were asked to examine if anyone had caused the problems five major themes emerged. The most common idea reported by participants was that people used supernatural means, such as spirits or Obeah to harm them (14/60). Participants also commonly felt that maltreatment from family members $(12 / 60)$ or maltreatment from others $(11 / 60)$ had caused their difficulty. A smaller proportion attributed the problems to heredity (3/60) and lack of financial support (2/60). Several themes also emerged when participants reported their belief as to the overall cause of their current problems. More than a third of the participants expressed the belief that it was as a result of supernatural factors (23/60). Slightly less than a third stated that it was a lack of support (17/60). A smaller proportion revealed that the overall cause of the problem was as a result of hereditary (5/60) or smoking weed (marijuana). A few participants also believed that they had in some way caused their own problems to occur $(3 / 60)$.

\section{Patients' encounter with western and traditional practitioner}

As seen in Table 3, the following ideas emerged as it relates to participants expectations of the western practitioner. Over one third wanted the western practitioner to make the situation better (34/60). Less than a third wanted to get medication and be sent home (12/60), while others expressed that they had no expectations (10/60) or were simply fulfilling their relatives' expectations by visiting the doctor (3/60). A smaller proportion revealed that they wanted the western practitioner to take care of the physical (as they had knowledge of the spiritual) or to counsel or talk with them (5/60). Lastly 2 out of 60 participants revealed that they wanted the western practitioner to show that they were sane. The general expectations of those that visited the traditional practitioner were as follows: A notable majority $(22 / 30)$ of the participants wanted the practitioner to free them from spiritual torment. Just over half wanted the practitioner to use rituals to help (17/30) and 16 out of 30 revealed that they wanted the traditional practitioner to use herbs to help them.

Table 3. Participants' Expectations of the Practitioners

\begin{tabular}{|c|c|c|}
\hline Expectations & $\mathrm{N}$ & $\%$ \\
\hline \multicolumn{3}{|l|}{ Western Practitioner $(\mathrm{N}=60)$} \\
\hline To make the situation better & 34 & 56.7 \\
\hline To get medication and sent home & 12 & 20.0 \\
\hline No expectations I was forced to go & 10 & 16.7 \\
\hline To take care of the physical (I had knowledge of the spiritual) & 5 & 8.3 \\
\hline \multicolumn{3}{|l|}{ To counsel or talk } \\
\hline I was only fulfilling my relatives' expectation & 5 & 8.3 \\
\hline \multirow[t]{2}{*}{ To show that I am sane } & 3 & 5.0 \\
\hline & 2 & 3.3 \\
\hline \multicolumn{3}{|l|}{ Traditional Practitioner $(\mathrm{N}=30)$} \\
\hline \multicolumn{3}{|l|}{ Free me from spiritual torment } \\
\hline Use rituals to help me & 22 & 73.3 \\
\hline \multirow[t]{2}{*}{ Use herbs to help me } & 17 & 56.7 \\
\hline & 16 & 53.3 \\
\hline
\end{tabular}

As indicated in Table 4, participants revealed that the western practitioner were likely to take a number of actions when presented with the patients' complaints. All of the participants revealed that they were given medication (60/60). Less than a third revealed that the practitioner spoke to them (11/60). A smaller proportion revealed that they were referred to a psychologist or diagnosed with an illness (6/60). Only 2 out of 60 revealed that the practitioner listened to their concerns. On the other hand, the following themes emerged as it relates to the actions taken by the traditional practitioner. More than two thirds revealed that the practitioner used herbs (20/30). Two thirds revealed that the practitioner used olive oil (19/30). Just over half revealed that the 
practitioner taught them about the situation (17/30), prayed (16/30), gave them a bath or listened (15/60). A smaller proportion revealed that the practitioner laid hands on them (6/30) (see Table 4).

Table 4: Actions taken by the practitioner

\begin{tabular}{|c|c|c|}
\hline Actions & $\mathrm{N}$ & $\%$ \\
\hline \multicolumn{3}{|l|}{ Western Practitioner $(\mathrm{N}=60)$} \\
\hline \multicolumn{3}{|l|}{ Gave me medication } \\
\hline Talked & 11 & 18.3 \\
\hline Referred me to a psychologist & 6 & 10 \\
\hline Diagnosed me with an illness & 6 & 10 \\
\hline Listened to my concerns & 2 & 3.3 \\
\hline \multicolumn{3}{|l|}{ Traditional Practitioner $(\mathrm{N}=30)$} \\
\hline Used herbs & 20 & 66.7 \\
\hline Used olive oil & 19 & 63.3 \\
\hline He taught me about the situation & 17 & 56.7 \\
\hline Prayed & 16 & 53.3 \\
\hline Gave me a bath & 15 & 50.0 \\
\hline Listened & 15 & 50.0 \\
\hline Laid hands & 6 & 20.0 \\
\hline
\end{tabular}

More than half of the sample (34/60) revealed that there was something that was done by the doctor that impacted negatively on them. The majority were unhappy about the side effects of medication (29/60). The smaller portion spoke about the poor treatment on ward (3/60), the medication making the situation worse and initially being unhappy about the treatment (1/60). On the other hand, a notably small proportion of the sample revealed that they were unhappy about the treatment they received from the traditional practitioner. Complaints included not trusting the practitioner (2/30), the treatment not working (2/30) and not getting much from him (2/30) (see Table 5).

Table 5: Was there anything that you were unhappy about with the doctor $(\mathrm{N}=60)$

\begin{tabular}{|c|c|c|}
\hline Unhappiness with the Practitioner & $\mathrm{N}$ & $\%$ \\
\hline \multicolumn{3}{|l|}{ Western Practitioner $(\mathrm{N}=60)$} \\
\hline Side effects of the medication & 29 & 58.0 \\
\hline Did not like how I was treated on the ward & 3 & 6.0 \\
\hline The medication made things worse & 1 & 2.0 \\
\hline At first I was & 1 & 2.0 \\
\hline \multicolumn{3}{|l|}{ Traditional Practitioner $\quad(\mathrm{N}=30)$} \\
\hline I do not trust him & 2 & 6.6 \\
\hline It did not work & 2 & 6.6 \\
\hline I did not get much from him & 2 & 6.6 \\
\hline
\end{tabular}

\section{Western practitioners' attitudes towards traditional, herbal and alternative medicine}

As illustrated in Table 6 western practitioners are of the opinion that traditional medicine is not a waste of time: alternative medicine (26/30), traditional healing (26/30) and the traditional herbalist (23/30). More specifically when it comes to treating mental illnesses more than two thirds of the western practitioners believe that the traditional herbalist and alternative medicine (23/30) have a true impact. The numbers differed slightly for traditional healing, in that less than two thirds (18/30) of western practitioners believe that the traditional healer has a true impact on the treatment of mental disorders. Emotionally western practitioners do not feel that they have any strong feelings towards traditional healing, traditional herbalist (21/30) and alternative medicine (20/30).

When asked if incorporating these traditional modalities in the healthcare system would bring a negative impact on the treatment of mental illnesses western practitioners had the following responses: Less than one third believed that alternative medicine will have a negative impact and more than a third felt that traditional herbalist (13/30) and the traditional healing (12/30) will bring about major negative impact. One can therefore conclude that when asked from different angles about the impact of traditional medicine on the treatment of mental illness, western practitioners' responses remain the same. In that they are more incline to view alternative medicine more positively than they would for traditional healer and herbalist. Western practitioners do believe that patients do have strong feelings towards alternative medicine (27/30), Traditional herbalist (26/30) and Traditional healers (22/30) (see Table 6). 
Table 6: Western Practitioners' Perception of the usefulness of Traditional medicine in treating mental illness $(\mathrm{N}=30)$

\begin{tabular}{|l|c|c|}
\hline Variable & $\mathrm{N}$ & $\%$ \\
\hline This method is a waste of time & 9 & 30.0 \\
Traditional Healers & 7 & 23.3 \\
Tradition Herbalist & 4 & 13.3 \\
Alternative Medicine & & \\
This method has no true impact on & 12 & 40.0 \\
the treatment of mental illness & 10 & 33.3 \\
Traditional Healers & 7 & 23.3 \\
Tradition Herbalist & & 30.0 \\
Alternative Medicine & 9 & 30.0 \\
No strong feeling about: & 9 & 30.0 \\
Traditional Healers & 9 & \\
Tradition Herbalist & 12 & 40.0 \\
Alternative Medicine & 12 & 41.4 \\
This is advantageous in treating mental illness & 14 & 46.7 \\
Traditional Healers & & \\
Tradition Herbalist & & \\
Alternative Medicine & 11 & 36.7 \\
Major positive impact on mental illness when & 9 & 30.0 \\
integrated with Western Medicine & 13 & 43.3 \\
Traditional Healers & & \\
Tradition Herbalist & & \\
Alternative Medicine & & \\
& & \\
\hline
\end{tabular}

A half of the western practitioners evaluate traditional healing as posing a moderate to extreme threat to the patient's treatment (15/30). Less than a third (7/30) hold the belief that it could offer patients moderate to extreme benefits and less than a third (6/30) felt that it offered no effect on patients' treatment. Only 2 out of 30 participants revealed that the Traditional healers offer a combination of both threat and benefit. The evaluation made of the Traditional herbalist was more positive as less than one third (8/30) felt that it offered patients moderate to extreme threats. A third (10/30) felt that it offered moderate to extreme benefits. One third are of the opinion that Traditional herbalist had no effect on patient treatment (10/30). Of the three nonbiomedical methods alternative medicine was given the highest positive ratings, as more than half (16/30) of the sample felt that it offered patients moderate to extreme benefits in treating their mental illness. Less than a third $6 / 30$ felt that alternative medicine offered moderate to extreme threat.

\section{Referral to traditional health practitioners}

In general very few western practitioners revealed that they referred patients to traditional practitioners. Less than one third (4/30) referred patients to the alternative medicine practitioners, referred to the traditional herbalist (3/30) and lastly the traditional healer (2/30). There were more referrals made to western practitioners from the traditional practitioners. In that there were twice as many referrals from the alternative medicine practitioners ( 8 vs. 4) to the western practitioners and from the traditional healer to the western practitioner ( 4 vs. 2). Lastly the traditional herbalist referred 4 patients to the western practitioner (see Table 7).

Table 7: Western Practitioners Referral of Psychiatric Patients $(\mathrm{N}=30)$

\begin{tabular}{|l|c|c|}
\hline Variable & N & $\%$ \\
\hline Traditional Healer & 2 & 6.7 \\
$\quad$ Referred patients to & 4 & 13.3 \\
Received Referral from & & \\
Traditional Herbalist & 3 & 10.0 \\
$\quad$ Referred patients to & 4 & 17.4 \\
Received Referral from & & 13.8 \\
Alternative Medicine & 4 & 26.7 \\
$\quad$ Referred patients to & 8 & \\
Received Referral from & & \\
\hline
\end{tabular}

The majority of the western practitioners are unlikely to recommend a patient to a traditional healer in the future (25/30). More than two thirds also felt that it was unlikely that they would refer patients to the herbalist (22/30). Western practitioners seemed more inclined to refer patients to alternative medicine when compared to the other traditional modes of 
treatment as more than a third was unlikely to refer a patient to an alternative medicine practitioner (14/30). Table 8 illustrates reasons western practitioners would refer patients to traditional practitioners in the future. Of the three treatment modalities western practitioners displayed more confidence in alternative medicine. Areas such as the patients' belief that treatment can work, the practitioner having a good reputation, western practitioners knowing that the treatment works and none specific complaints will be explored. Approximately two thirds (18/30) of western practitioners were more inclined to refer patients to the alternative practitioner because of the patients interest. Patients' interest in traditional herbal and healing were rated much lower at $12 / 30$ and $9 / 30$ respectively. More than a third of western practitioners would refer patients to the alternative practitioner because they know that his treatment works and because the alternative practitioner has a good reputation (11/30; 10/30). Traditional herbalists and healers were evaluated less positively in this regard as less than a third of western practitioners would refer patients to these practitioners because of the practitioners have a good reputation and because their treatment work (7/30; 6/30). Lastly more than a third would refer patients to the traditional herbalist because of the patients' have non-specific complaints (12/30). Western practitioners were less likely to refer patients with non-specific complaints to the alternative practitioner or traditional healer $(2 / 30 ; 1 / 30)$.

Table 8: Reasons why Western Practitioners' would Refer Patients to Traditional Practitioners $(\mathrm{N}=30)$

\begin{tabular}{|l|c|}
\hline Variable & $\mathrm{N}(\%)$ \\
\hline Traditional Healer & $9(31.0)$ \\
Patient's belief that it can work & $1(3.6)$ \\
As a last resort & $6(21.4)$ \\
This Practitioner has a good reputation & $6(20.7)$ \\
Because I know it work & $6(20.7)$ \\
Personally found it beneficial & $1(3.4)$ \\
None Specific complaints & $12(41.4)$ \\
Traditional Herbalist & $6(21.4)$ \\
Patient's belief that it can work & $7(25)$ \\
As a last resort & $7(24.1)$ \\
This Practitioner has a good reputation & $2(6.9)$ \\
Because I know it work & $12(40)$ \\
Personally found it beneficial & \\
None Specific complaints & $18(64.3)$ \\
\hline Alternative Medicine & $8(28.6)$ \\
Patient's belief that it can work & $10(40.0)$ \\
As a last resort & $11(42.3)$ \\
This Practitioner has a good reputation & $6(22.2)$ \\
Because I know it work & $2(7.7)$ \\
Personally found it beneficial & \\
None Specific complaints &
\end{tabular}

\section{Discussion with patient about traditional healing, herbal treatment and alternative medicine}

As shown in Table 9 for the most part not many western practitioners discussed with their patients the potential benefits or harmful effects of using traditional healing. Almost half of the western practitioners were more inclined to discuss with patients the harmful effects of using traditional healing (13/30). On the other hand approximately half of the western practitioners reported that patients were more likely to discuss the benefits of using traditional healing (14/30). Western practitioners had similar reviews for traditional herbalist as they did traditional healing. In that generally the majority does not have open discussions with patients about the use of this treatment. Approximately half of the western practitioners have discussed with patients the harmful effects of using herbal treatment (14/30) and less than a third of these discussions were initiated by the western practitioner. Contrary to their discussions of the harmful effects, approximately half of the western practitioners have revealed that patients have initiated discussions with them about the benefits of using traditional herbal treatment (12/30). Unlike traditional healing and herbal medicine, generally western practitioners have had discussions about the benefits of using alternative medicine than they do about the harmful effects. More than a third of the western practitioners have discussed the benefits of using alternative medicine with the patients (11/30). A half has admitted to patients initiating discussions about the benefits with them about using alternative medicine.

Table 10 illustrates western practitioners' evaluation of the treatment outcomes of traditional healing, herbal and alternative medicine. More than two thirds $(18 / 30)$ of the sample revealed that alternative medicine had some positive treatment outcomes. Less than a third (9 30$)$ felt that there traditional healing had some positive treatment outcome and only 7 out of 30 felt that it had some positive treatment outcome. On the other hand 8 out of 30 felt that the treatment outcome of the traditional healer resulted in major negative outcomes 
Table 9: Western Practitioners discussion with patients about the benefits or dangers in utilizing Traditional medicine $(\mathrm{N}=30)$

\begin{tabular}{|c|c|c|c|}
\hline Discussion items & $\begin{array}{l}\text { Traditional } \\
\text { Healer } \\
\text { N }(\%)\end{array}$ & $\begin{array}{l}\text { Traditional } \\
\text { herbalist } \\
\mathbf{N}(\%)\end{array}$ & $\begin{array}{l}\text { Alternative } \\
\text { medicine } \\
\mathbf{N}(\%)\end{array}$ \\
\hline $\begin{array}{l}\text {-Discussed benefits about using } \\
\text {-You initiated discussion of the benefits } \\
\text {-The Patient initiated discussion of the benefits } \\
\text {-Both you and the patient initiated discussions } \\
\text { of benefits } \\
\text {-Discussed harmful effects of using } \\
\text {-You initiated discussion of the harmful effects } \\
\text {-The Patient initiated discussion of the harmful effects } \\
\text {-Both you and the patient initiated discussions } \\
\text { of harmful effects }\end{array}$ & $\begin{array}{l}5(17.2) \\
3(10.3) \\
14(47) \\
2(8.7) \\
13(44.8) \\
8(28.6) \\
7(26.9) \\
3(12.0)\end{array}$ & $\begin{array}{l}6(20.7) \\
2(6.9) \\
12(44.4) \\
2(6.7) \\
14(48.3) \\
9(32.1) \\
3(12) \\
1(3.8)\end{array}$ & $\begin{array}{l}11(37.9) \\
8(27.3) \\
14(50.0) \\
8(32.0) \\
7(24.1) \\
3(10.7) \\
3(10.7) \\
2(7.7)\end{array}$ \\
\hline
\end{tabular}

Table 10: Western Practitioners' evaluation of Traditional healing, faith healing or alternative medicine treatment outcomes ( $\mathrm{N}$ $=30$ )

\begin{tabular}{|l|l|l|l|l|}
\hline Treatment outcome & Traditional healing & Herbalist & $\begin{array}{l}\text { Alternative } \\
\text { medicine }\end{array}$ & Biomedicine \\
\cline { 2 - 5 } & $\mathrm{N}(\%)$ & $\mathrm{N}(\%)$ & $\mathrm{N}(\%)$ & $\mathrm{N}(\%)$ \\
\hline Major positive & $1(3.3)$ & & $1(3.3)$ & $20(66.7)$ \\
\hline Some positive & $7(23.3)$ & $9(30)$ & $18(60.0)$ & $8(26.7)$ \\
\hline Neither & $4(13.3)$ & $4(13.3)$ & $1(3.3)$ & $1(3.3)$ \\
\hline Some negative & $3(10)$ & $3(10)$ & $3(10)$ & $1(3.3)$ \\
\hline Major negative & $8(26.7)$ & $3(10)$ & & \\
\hline Don't know & $5(16.7)$ & $10(33.3)$ & $7(23.3)$ & \\
\hline Missing cases & $2(6.7)$ & & & \\
\hline
\end{tabular}

\section{Discussion}

The study among psychiatric patients in Jamaica found that more than a third of the participants expressed the belief that the overall cause of their mental illness was as a result of supernatural factors (23/60). In general, the majority of patients felt that their perception of their problems did not concur with the western practitioner, which in turn caused distress for these patients. In this case for those who seek both traditional and western medicine, there was a difference in patients' relationship with the traditional practitioner. Patients expressed that when interacting with the traditional practitioner, they felt that they have been listened to and that they had the opportunity to speak about the problems they have been experiencing. If the causes of their problem are congruent with that of the practitioner's explanation, they are more inclined to feel pleased about their interaction and the treatment they receive. Among psychiatric patients in south India it was found that an average of $30 \%$ of patients claimed some benefit from healer consultation, although the majority (91\%) had discontinued such treatment at the time of the hospital attendance (Campion and Burgra, 1997). Abbo, Ekblad, Waako, Okello and Musisi (2009) studied mental illnesses handled by traditional healers in Uganda and found that patients with moderate to severe symptoms were more likely to use both biomedical services and traditional healers. Mental health professionals therefore need to come up with ways to co-operate with traditional healers for the benefit of their patients.

The study among western trained practitioners found that although they acknowledged that traditional medicine plays a major role in the treatment of mental illness among psychiatric patients the treatment was not advantageous. For the most part when all three traditional approaches were examined alternative medicine seemed more favourable than traditional healing and traditional herbal treatment. Traditional herbal treatment was the least favourable amongst the three. Western practitioners have noted that patients were more inclined to initiate discussions on their use of traditional medicine and its potential benefits. Western practitioners tended to have a negative view of traditional medicine as they perceive this treatment modality to be 
harmful when treating mental illnesses. Currently the majority of western practitioners is not open to patient's use of this mode of treatment, but would be inclined to be open if provided with more information and scientific evidence that it works.

Westberg (as cited in Griffiths, 1983) has advocated a holistic care concept, in which he has proposed the collaboration between Western Biomedically trained physicians and religious leaders in the diagnosis and treatment of patients. He sought to legitimize the role of the church in the healing process by purporting that healing is a natural ministry of the church. Healing in the church could help individuals to move towards a more mature faith in God and this in turn could impact on bodily reactions which would make the individuals enjoy greater health. The holistic approach to clinic care would encompass the spiritual, mental and corporal components of the human being. It is believed that one becomes more vulnerable to disease when you alienate yourself from God through sin; as such, curative intervention would have been most successful when the individual moves towards reconciliation with God (Griffiths, 1983)

While not disputing the fact that there exists the use of traditional medicine among their patients, Western practitioners tend to be strong advocates of the scientific method. Additionally it is also argued that Western biomedical practitioners cannot accept a liberalized healthcare system as this reduces their dominance and produces competition (Weaver, 2003). Western medicine in believing that their approach was the most effective approach to health, regarded traditional medicine as "weird and outlandish, clearly a product of ignorance and superstition.... unscientific and virtually untestable". Western medicine's approach to the diagnosis of ill health on the other hand, is thought to be more effective as they view their approach as "rational and scientific" (Hayes \& Watrall, 2000 p.1).

To be more specific, it has also been argued that Western practitioners lack understanding when patients attribute their illnesses to anything other than that which is scientific. This lack of understanding, researchers reveal, is due largely to the fact that Western practitioners tend to have the misconception that deeply held beliefs and values that their patients have towards their illness can be changed through rational reasoning. Therefore Western practitioners may think that if they show the patients how rational their approach is as opposed to the patient's approach to his/her illness then the patient will comply. The result can be a catastrophe when Western Practitioners refuse to acknowledge the patients' approach to health and as such force them to follow Western medicine's approach. Elaine and John Cunning in reporting the ultimate demise of one mental health programme commented:

"It was evident that we have been trying to change ideas that were deeply held and that the more we tried to dislodge them the more tightly people held to them and angrier they become at us for trying to take them away" (Simon and Pardes, 1977, p.174). From as early as 1966, Beaubrun (1966) in the Caribbean stated:

"it would be a mistake to underestimate the importance and influence of these religio-magic practitioners. They have a head start over the orthodox middle class practitioner of medicine in that their ideas of the aetiology of mental illness are shared by their patients and they are much better grounded in the culture than he." (p.54)

Beaubrun (1966) warned that although patients do seek balms it is illegal to do so. He advises that balm is a practice that is lacking in prestige. Psychiatrist should not promote collaboration with traditional healers as happens in Nigeria (Wedenoja, 1983). Western biomedical physicians often reject requests from their patients to incorporate spiritual healing in their treatment because the scientific has been legitimized and has, '...proven objective' advances in the reduction of morbidity, disease progression or hospital readmission (Miller \& Thoresen, 2003 p.24).

The findings clearly indicate that despite western practitioners' negative views towards patient's use of traditional medicine, patients continue to do so. Perhaps patients' motivation to utilize traditional medicine stems from their strong Afrocentric beliefs that the spiritual world can help in healing their illnesses or it could be their appreciation of the approach taken by the traditional practitioners. There is much to be learnt about patients' interaction with the traditional practitioners, for starters patients are of the opinion that traditional practitioners have a greater understanding to their problem and take time to listen and explain what the problem is. Whilst this is not to say that western medicine is less beneficial than traditional medicine, it is clear that what the patients are saying is that there is a need for a more integrated approach that caters to the physical as well as spiritual concerns. With that being said, there is a need to develop models of collaboration that promote a workable relationship between the two healing systems in treating mental illness. A limitation of the study is that the numbers were small and therefore cannot be generalized to the wider psychiatric population. It however provides a useful starting point when exploring common perspectives among practitioners about psychiatric patients use of alternative and traditional medicine especially in a context patients are in strong favour of traditional and alternative medicine.

\section{References}

1. Abbo, C., Ekblad, S., Waako, P., Okello, E. and Musisi, S. (2009). The prevalence and severity of mental illnesses handled by traditional healers in two districts in Uganda. Afr Health Sci, 9 Suppl 1: S16-22.

2. Beaubrun, M.H. (1966). Psychiatric education for the Caribbean. West Indian Med J, 15: 52-62.

3. Bhui, K. and Bhugra, D. (2002). Explanatory models for mental distress: implications for clinical practice and research. Br J Psychiatry, 181:6-7. doi: 10.1192/bjp.181.1.6.

4. Boucher TA \& Lenz SK. (1998). An organization survey of physicians' attitudes and practice of alternative and complementary medicine. Alternative Therapies in Health and Medicine, 4(6), 59-65.

5. Campion,J. and Bhugra, D. (1997). Experiences of religious healing in psychiatric patients in south India. Soc Psychiatry Psychiatr Epidemiol, 32(4):215-21.

6. Giffiths, E.E.H. (1983). The significance of ritual in a Church-Based healing model. Am J Psychiatry, 140: 5-24. 
7. Hayes, M. and Watrall, E. (2000). The Asclepion. Bloomington: Indiana University Press.

8. Hickling, F.W. (1975). Psychiatric care in a general hospital unit in Jamaica. West Indian Med J, 24: 635-37.

9. James, C. (2008). Counting spirits with my fellow travellers. Opposing worldviews: Western and Traditional medicine. Kingston, Jamaica: PhD Thesis, The University of the West Indies.

10. James, C., Weaver, S. and Morgan, K. (2004). Psychiatric patient's evaluation of the efficacy of traditional medicine versus western medicine. Kingston, Jamaica: Master's thesis, The University of West Indies.

11. Jorm, F.A. (2000). Mental health literacy. Public knowledge and beliefs about mental disorders. Br J Psychiatry, 177: 296-401.

12. Kiev, A. (1963). Beliefs and delusions of West Indian migrants to London. Br J Psychiatry, 109:460: 356-63.

13. Llyod, R.K., Jacob, S.K., Patel, V., Louis S.T.L., Bhugra, D. and Mann, A.H. (1998). The development of the short explanatory model interview (SEMI) and its use among primary-care attenders with mental disorders. Psychol Med, 26: 12311237.

14. Miller, W.R. and Thoresen, C.E. (2003). Spirituality, religion, and health. An emerging research field. Am Psychol, 58(1): 24-35.

15. Ministry of Justice (2006). Obeah Act. Retrieved May 11, 2009 from http://www.moj.gov.jm/law/search?page=5\&lawSearch=Criminal\%20Justice

16. Peltzer, K. (2001). Attitudes of physicians toward traditional healing, faith healing and alternative medicine in rural South Africa. Geneeskunde - The Medicine Journal, 43(7): 35-42.

17. Peltzer, K. and Machleidt, W. (1992). A traditional (African) approach towards the therapy of schizophrenia and its comparison with western models. Therapeutic Communities, 13: 4-18.

18. Rowe, M.M. and Allen, R.G. (2003). Spirituality as a means of coping with chronic illness. Am J Health Stud, 19(1): 62-66.

19. Sumathipala, A., Siribaddana, S., Hewege, S., Sumathipala, K., Prince, M. and Mann, A. (2008). Understanding the explanatory model of the patient on their medically unexplained symptoms and its implication on treatment development research: a Sri Lanka Study. BMC Psychiatry, 8;8:54.

20. Sharif, S.A. and Ogunbanjo, G.A. (2003). Non-compliance to treatment among patients suffering from psychiatric illnesses in Mmametlhake health district, South Africa. S Afr Family Practice, 45(4):10-13.

21. Simon, R.C. and Pardes, H. (1977). Understanding human behaviour in health and illness. New York: The Williams and Wilkins Company. Waverly Press INC.

22. Weaver, S. (2003). Health and illness in rural community. A study of traditional healthcare practices in the parish of St. Thomas. Kingston: PhD thesis. The University of the West Indies.

23. Wedenoja, W. (1983). Jamaican psychiatry. Transcultural Psychiatry, 20: 233.

24. Wittkower, D.E. (1970). Transcultural psychiatry in the Caribbean: Past, present and future. Am J Psychiatry, 127: 162166. 